\title{
Linezolid pharmacokinetics in critically ill patients with renal replacement therapy: comparison of equi-dose of continuous veno-venous haemofiltration with continuous veno-venous haemodiafiltration
}

\author{
C Roger $^{1}$, B Louart ${ }^{1 *}$, L Muller$^{1}$, JA Roberts ${ }^{2}$, JY Lefrant $^{1}$
}

From ESICM LIVES 2015

Berlin, Germany. 3-7 October 2015

\section{Introduction}

Linezolid is a commonly used antibiotic for difficult-totreat Gram-positive infections for which little data is available to guide dosing for different types of renal replacement therapy.

\section{Objectives}

The objective of this study was to compare the population pharmacokinetics of linezolid during continuous venovenous haemofiltration (CVVHF, $\left.30 \mathrm{~mL} \cdot \mathrm{kg}^{-1} \cdot \mathrm{h}^{-1}\right)$ and continuous venovenous haemodiafiltration (CVVHDF, $15 \mathrm{~mL} \cdot \mathrm{kg}^{-1} \cdot \mathrm{h}^{-1}+15 \mathrm{~mL} \cdot \mathrm{kg}^{-1} \cdot \mathrm{h}^{-1}$ ). We then sought to perform Monte Carlo dosing simulations to determine doses that best achieve pharmacodynamic targets for these patients.

\section{Methods}

Patients with a clinical indication for linezolid and prescribed either CVVHF or CVVHDF were eligible for participation in this prospective pharmacokinetic study. Patients were administered $600 \mathrm{mg}$ IV 12-hourly. Seven blood samples were collected over one dosing interval and analysed by a validated chromatographic method. Population pharmacokinetic analysis was undertaken using Pmetrics and Monte Carlo simulations evaluated achievement of a pharmacodynamics target of an area under the concentration-time curve from 0-24 hours to minimum inhibitory concentration $\left(\mathrm{AUC}_{0-24} / \mathrm{MIC}\right)$ of 80 .

${ }^{1}$ Nimes University Hospital, Nimes, France

Full list of author information is available at the end of the article

\section{Results}

9 CVVHDF and 8 CVVHF were performed in 13 patients. Patient characteristics regimens of CVVHDF and CVVHF were similar. A two compartment linear model best described the data. CVVHDF was associated with a $20.5 \%$ higher mean linezolid clearance than CVVHF, without statistical significance $(\mathrm{P}=0.39)$. Both increasing patient weight and decreasing SOFA score were associated with increasing linezolid clearance. The mean (SD) parameter estimates were clearance 3.8 (2.2) $\mathrm{L} / \mathrm{h}$, volume of the central compartment 26.5 (10.3) L, intercompartmental clearance constants from central to peripheral (Kcp) 8.1 (12.1) L/h and peripheral to central compartments (Kpc) 3.6 (4.0) L.h ${ }^{-1}$. Achievement of pharmacodynamics targets was low for a MIC of $2 \mathrm{mg} / \mathrm{L}$ with the studied dose.

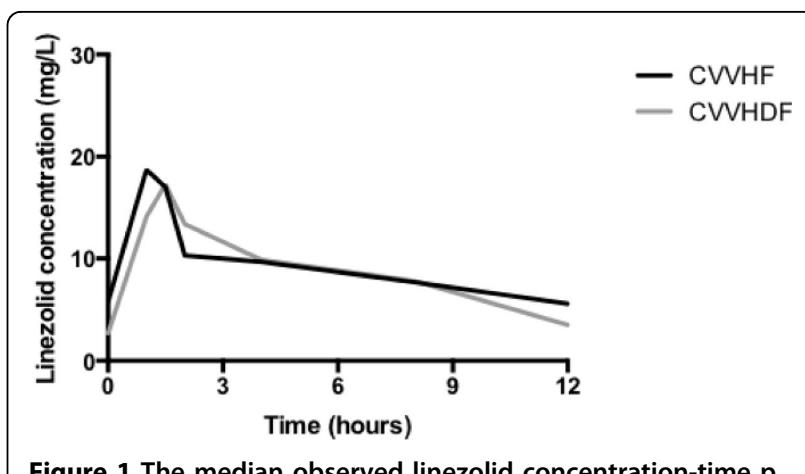

Figure 1 The median observed linezolid concentration-time $p$. 


\section{Conclusions}

The present data indicates profound pharmacokinetic variability of linezolid during CVVHF and CVVHDF. Sub-optimal achievement of therapeutic targets occurs at the EUCAST breakpoint MIC of $2 \mathrm{mg} / \mathrm{L}$ using $600 \mathrm{mg}$ IV 12-hourly.

\section{Authors' details}

${ }^{1}$ Nimes University Hospital, Nimes, France. ${ }^{2}$ University of Queensland,

Brisbane, Australia.

Published: 1 October 2015

doi:10.1186/2197-425X-3-S1-A631

Cite this article as: Roger et al.: Linezolid pharmacokinetics in critically ill patients with renal replacement therapy: comparison of equi-dose of continuous veno-venous haemofiltration with continuous veno-venous haemodiafiltration. Intensive Care Medicine Experimental 2015 3(Suppl 1): A631.

\section{Submit your manuscript to a SpringerOpen ${ }^{\odot}$ journal and benefit from:}

- Convenient online submission

- Rigorous peer review

- Immediate publication on acceptance

- Open access: articles freely available online

- High visibility within the field

- Retaining the copyright to your article 